\title{
Morphometric, Meristic, and Growth Patterns of the Strombus turturella from the Dompak Island Coastal Area, Tanjungpinang Kepulauan Riau
}

\author{
Henny $^{1 *}$, Eddiwan $^{2}$, Efawani $^{2}$ \\ ${ }^{1}$ Student of The Faculty of Fisheries And Marine Science University of Riau, Pekanbaru \\ ${ }^{2}$ Lecturer at the Faculty Of Fisheries And Marine Science University Riau, Pekanbaru \\ *Hennyphy327@gmail.com
}

\begin{abstract}
Strombus turturella is a type of gastropods that live in the shallow coastal area of the Dompak Island. A research aims to understand the morphometrical, meristical characteristics and growth patterns of $S$. turturella from the Dompak Island was conducted in June-July 2018. The number of snail sampled was 400, with 46.98-83.07 TL mm and 13-46 grams BW. There were six morphological characteristics measured, there were total length, shell length, aperture length, shell width, shell depth and lip thickness, and there was one meristical characteristic count, namely the number of spire. Results shown that there are 5 morphometrical characteristic differences in males and females. Total length of male is longer than that of the female. While other characteristics, such as the shell length and aperture of the females were longer, the shell was wider, deeper and the lip was thicker than those of the males. The number of spire was 4-9 in males and 4-8 in females. The lenghweight relationship shown that the growth of males and females is allometric negative $(b=0.503)$.
\end{abstract}

Keywords: Intertidal zone, Shallow coastal, Gastropods, Allometrik negative.

\section{PENDAHULUAN}

Siput gonggong atau Strombus turturella adalah keluarga Gastropoda, yang memiliki karakteristik seperti operkulum yang pipih panjang, mirip pisau berduri, serta dapat digunakan sebagai alat gerak di atas pasir atau lumpur. Selain itu hewan ini memiliki ulir yang meningkat di sepanjang cangkangnya dan lekukan stromboid.

Siput gonggong merupakan salah satu jenis Gastropoda yang sangat digemari penduduk, sehingga penangkapan bintang ini terus meningkat, sehingga populasi siput ini kian hari kian menurun, dan kualitas siputnyapun makin rendah. Oleh karena itu perlu adanya upaya pengelolaan untuk melindungi keberlanjutan spesies gastropoda ini di alam. Salah satu langkah dalam pengelolaan sumberdaya siput gonggong itu adalah dengan mengkaji aspek biologi, seperti morfometrik, meristik dan pola pertumbuhan.

\section{BAHAN DAN METODE}

Penelitian dilaksanakan pada bulan Juni - Juli 2018. Sampel siput gonggong diambil dari Perairan Laut Pulau Dompak, Kota Tanjungpinang, Provinsi Kepulauan Riau. Pengamatan dan pengukuran morfometrik siput gonggong dilakukan di Laboratorium Balai Benih Ikan Pengujan, Kabupaten Bintan, Provinsi Kepulauan Riau. 


\section{Perhitungan Morfometrik}
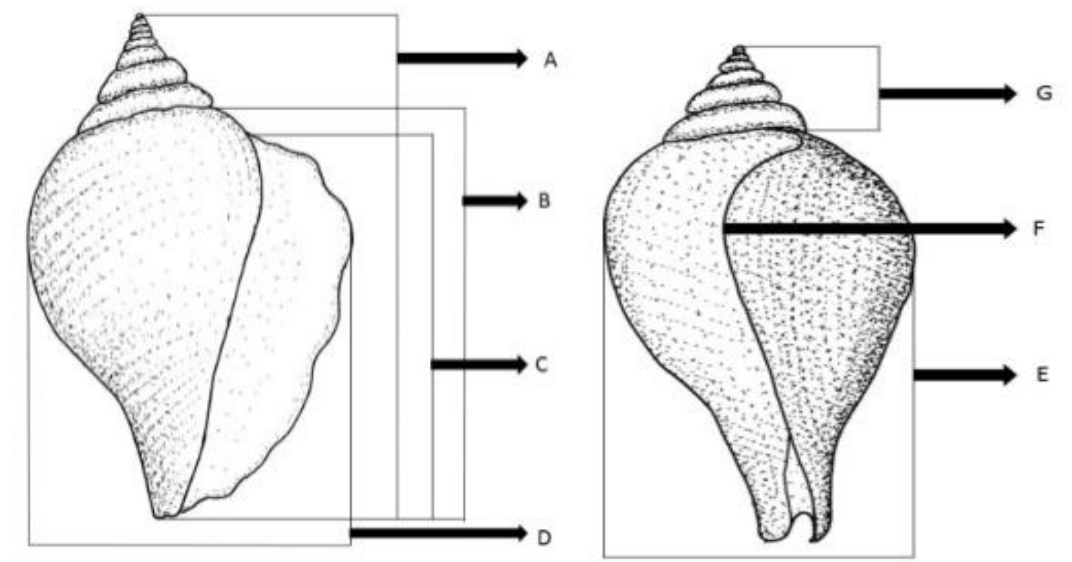

Gambar 1. Sketsa Pengukuran Morfometrik Siput Gonggong

Keterangan :

$\mathrm{A}=$ Panjang total $(\mathrm{PT})$

$\mathrm{B}=$ Panjang Baku (PB)

$\mathrm{C}=$ Lebar Bukaan Cangkang (LBC)

\section{Perhitungan Meristik}

Setelah dilakukan pengukuran morfometrik, maka dilakukan perhitungan meristik siput gonngong. Perhitungan meristik dilakukan berdasarkan Cob et al., (2008). Bagian siput gonggong yang dihitung adalah jumlah menara (tingkatan) pada cangkang siput gonggong. Data hasil pengukuran meristik yang didapatkan dianalisis dengan melihat kisaran jumlah karakteristik meristik.

\section{Hubungan Panjang Berat}

Untuk melihat hubungan antara berat (W) badan dengan panjang cangkang (L) (Eddiwan et al., 2017):

Keterangan:

$$
\mathrm{W}=\mathrm{aL}^{\mathrm{b}}
$$

$\mathrm{W}=$ berat siput (gram)

$\mathrm{L}=$ panjang cangkang $(\mathrm{mm})$

1. Jika nilai $b=3$ maka pertumbuhan berat adalah isometrik.

2. Jika nilai $b$ \# 3 maka pertumbuhan berat adalah allometrik.

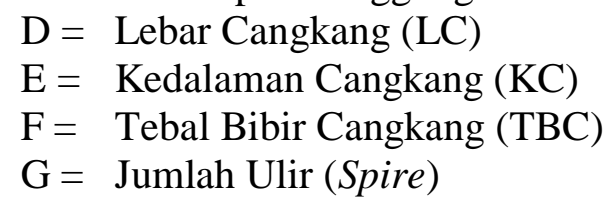

a. Jika $\mathrm{b}>3$ maka pertumbuhan berat adalah allometrik positif.

b. Jika $b<3$ maka pertumbuhan berat adalah allometrik negatif.

Nilai $b<3$ menunjukkan keadaan siput yang kurus dimana pertambahan panjangnya lebih cepat dari pertambahan beratnya dan nilai $b>3$ menunjukkan bahwa pertambahan berat lebih cepat dibandingkan dengan pertambahan panjang (Effendi, 2003).

\section{HASIL DAN PEMBAHASAN}

\section{Hasil Tangkapan Siput Gonggong ( $S$. turturella)}

Siput Gonggong (S. turturella) yang terkumpul dari hasil tangkapan selama penelitian adalah berjumlah 400 ekor. Komposisinya yaitu 103 jantan dan 297 betina, pengambilan siput gonggong dilakukan secara langsung dengan menggunakan tangan, dilakukan pada saat pagi hari yaitu pada saat terjadinya surut terendah pada lokasi pengambilan sampel. Adapun jumlah siput gonggong yang 
didapatkan selama penelitian dapat dilihat pada Tabel 1.

Tabel 1. Jumlah Siput Gonggong yang Didapatkan Selama Penelitian

\begin{tabular}{llccc}
\hline No & Pengamatan & $\begin{array}{c}\text { Jumlah Siput } \\
\text { (ekor) }\end{array}$ & $\begin{array}{c}\text { Betina } \\
\text { (ekor) }\end{array}$ & $\begin{array}{c}\text { Jantan } \\
\text { (ekor) }\end{array}$ \\
\hline 1 & Minggu pertama & 100 & 76 & 24 \\
2 & Minggu kedua & 100 & 74 & 26 \\
3 & Minggu ketiga & 100 & 81 & 19 \\
4 & Minggu keempat & 100 & 66 & 34 \\
\hline & Jumlah (1+2+3+4) & 400 & 297 & 103 \\
& Pesentase \% & 100 & 74,25 & 25,75 \\
\hline
\end{tabular}

Berdasarkan Tabel 1 diatas terlihat bahwa siput gonggong yang banyak tertangkap adalah siput betina yaitu 279 ekor $(74,25 \%)$. Sedangkan siput jantan sebanyak 103 ekor (25,75\%). Dari hasil penelitian ini didapatkan jumlah siput betina lebih banyak di bandingkan jantan pada setiap minggunya di perkirakan pada waktu pengambilan sampel pada bulan juni-juli termasuk kedalam musim pemijahan. Hasil penelitian ini sama dengan hasil penelitian siddik (2011), yaitu rasio kelamin (sex ratio) antara siput jantan dan betina selama pengamatan berkisar antara 0,35-0,51. Rasio ini memperlihatkan bahwa populasi siput betina lebih banyak dibandingkan dengan populasi siput

jantan. Hal ini diperkirakan saat pengambilan sampel pada bulan Mei-Juli yang merupakan bulan pemijahan untuk siput gonggong di Tl. Klabat.

\section{Morfologi Siput Gonggong turturella)}

$(S$.

Siput gonggong ( $S$. turturella) yang tertangkap di perairan Pulau Dompak adalah sebagai berikut: Kingdom: Animalia; Filum: Molluska; Kelas: Gastropoda; Subkelas: Prosobranchia; Ordo: Megagastropoda; Famili:
Stombidae; Genus: Srombus; Spesies: Strombus turturella (Groh dan Poppe, 1999).

Berdasarkan pengamatan selama penelitian, Siput gonggong memiliki ciriciri morfologi, sebagai berikut: bentuk cangkang lonjong (memanjang), bercangkang tipis bewarna gradasi emas kekuningan dimulai dari arah bukaan cangkang memutar sampai ke ujung bibir cangkang, Siput gonggong ini memiliki karakteristik seperti operculum yang pipih panjang, menyerupai gergaji yang tajam (berigi-rigi) pada bagian satu sisinya yang dapat digunakan sebagai alat gerak di atas pasir maupun lumpur. Selain itu siput gonggong memiliki ulir yang meningkat di sepanjang cangkangnya dan lekukan stromboid.

Secara morfologi organ reproduksi terdiri atas organ reproduksi luar dan organ reproduksi dalam. Organ reproduksi luar mudah terlihat apabila siput gonggong sedang aktif dengan mengeluarkan sebagian tubuhnya dari dalam cangkang. Organ reproduksi luar tersebut adalah penis pada siput jantan dan genital pore (lubang genital) dan vagina (female opening) pada siput betina dapat di lihat pada Gambar 2 . 


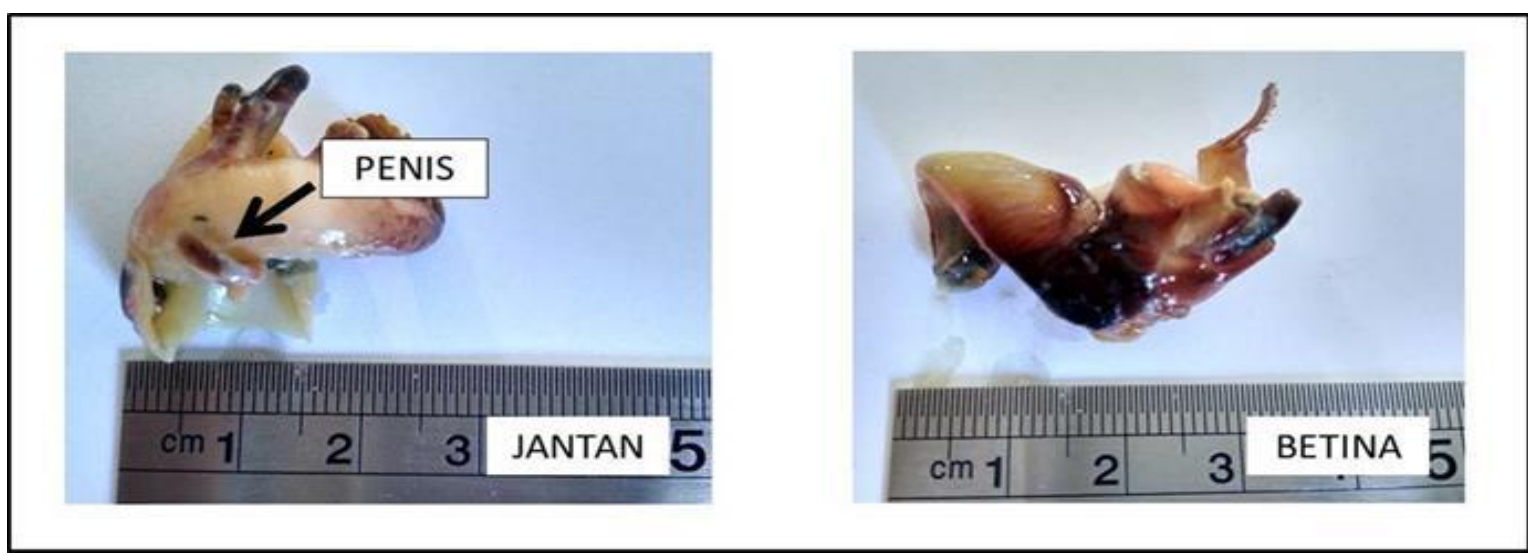

Gambar 2. Reproduksi luar siput gonggong

\section{Morfometrik Siput Gonggong ( $S$.} turturella)

Karakteristik morfometrik siput gonggong ( $S$. turturella) yang di ukur pada penelitian ini ada 7 karakter termasuk panjang total (PT). Panjang total dipilih untuk sebagai "acuan" dan hasil dari pengukuran 6 karakter lainnya dibandingkan dengan panjang total. Seluruh hasil pengukuran karakter morfometrik siput gonggong $(S$. turturella). Sedangkan ukuran maksimum dan minimum setiap karakter morfometrik dapat dilihat pada Tabel 2.

Tabel 2. Ukuran Maksimum dan Minimum Karakter Morfometrik Siput Gonggong

\begin{tabular}{llllll}
\hline \multirow{2}{*}{$\begin{array}{c}\text { Karakter } \\
\text { Morfometrik }\end{array}$} & \multicolumn{2}{l}{ Siput Betina } & \multicolumn{3}{c}{ Siput Jantan } \\
\cline { 3 - 6 } & & \multicolumn{3}{c}{ Mm } \\
\cline { 3 - 6 } & Paks & Min & Maks & Min \\
\hline $\mathbf{1}$ & PT & 83.07 & 46.98 & 72.44 & 48.27 \\
$\mathbf{2}$ & PB & 59.39 & 32.11 & 60.05 & 36.99 \\
$\mathbf{3}$ & LBC & 58.91 & 30.28 & 58.91 & 32.95 \\
$\mathbf{4}$ & LC & 49.86 & 21.15 & 49.86 & 23.93 \\
$\mathbf{5}$ & KC & 40.41 & 20.01 & 40.41 & 20.66 \\
$\mathbf{6}$ & TBC & 1.92 & 0.32 & 1.78 & 0.29 \\
\hline
\end{tabular}

Pada diatas dapat dilihat bahwa ukuran siput gonggong ( $S$. turturella) yang terkecil sampai ukuran terbesar adalah 46.98-83.07 mm. Siput gonggong jantan memiliki kisaran panjang total (PT) 48.27$72.44 \mathrm{~mm}$ sedangkan siput gonggong betina memiliki kisaran panjang total (PT)
46.98-83.07 mm, artinya ukuran Siput gonggong yang paling kecil dijumpai pada siput gonggong betina dan ukuran siput gonggong yang terpanjang dijumpai pada siput betina. Sedangkan nilai proporsi karakter morfometrik siput gonggong dapat dilihat pada tabel 3.

Tabel 3. Proporsi Karakter Morfometrik (\%) Terhadap Panjang Total (\%)

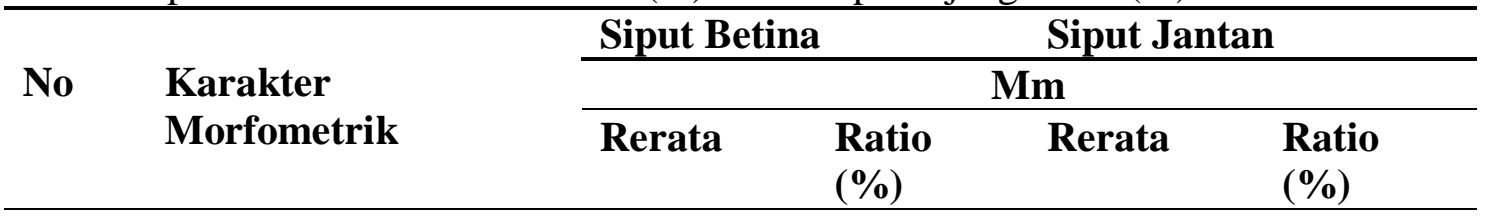




\begin{tabular}{|c|c|c|c|c|c|}
\hline \multirow{3}{*}{ No } & \multirow{3}{*}{$\begin{array}{l}\text { Karakter } \\
\text { Morfometrik }\end{array}$} & \multicolumn{2}{|c|}{ Siput Betina } & \multicolumn{2}{|c|}{ Siput Jantan } \\
\hline & & \multicolumn{4}{|c|}{ Mm } \\
\hline & & Rerata & $\begin{array}{l}\text { Ratio } \\
(\%)\end{array}$ & Rerata & $\begin{array}{l}\text { Ratio } \\
(\%)\end{array}$ \\
\hline 1 & PT & 58,18 & $12 / 7$ & 57,05 & $7 / 4$ \\
\hline 2 & PB & 78,35 & $9 / 7$ & 80,49 & $5 / 4$ \\
\hline 3 & $\mathrm{LBC}$ & 70,94 & $7 / 5$ & 72,63 & $11 / 8$ \\
\hline 4 & $\mathrm{LC}$ & 57,76 & $7 / 4$ & 59,94 & $5 / 3$ \\
\hline 5 & $\mathrm{KC}$ & 45,53 & $11 / 5$ & 44,83 & $9 / 4$ \\
\hline 6 & TBC & 1,57 & $131 / 3$ & 1,71 & $117 / 3$ \\
\hline
\end{tabular}

Pada penelitian ini setiap karakter morfometrik siput dihitung proporsinya terhadap panjang total, seperti $\mathrm{PB} / \mathrm{PT}$, LBC/PT, LC/PT, KC/PT dan TBC/PT. Tabel di atas menunjukkan bahwa karakter morfometrik antara siput gonggong jantan dan betina terdapat 5 perbedaan, yaitu pada karakter morfometrik panjang baku (PB), lebar bukaan cangkang (LBC), lebar cangkang (LC), kedalaman cangkang (KC) dan tebal bibir cangkang (TBC).

Pola sebaran data ukuran morfometrik seiring dengan pertambahan panjang total siput gonggong dapat dilihat pada grafik Gambar 3a-e.

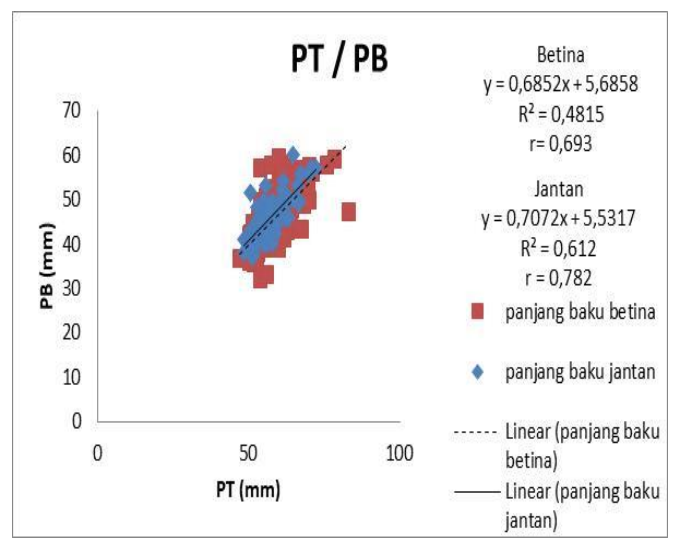

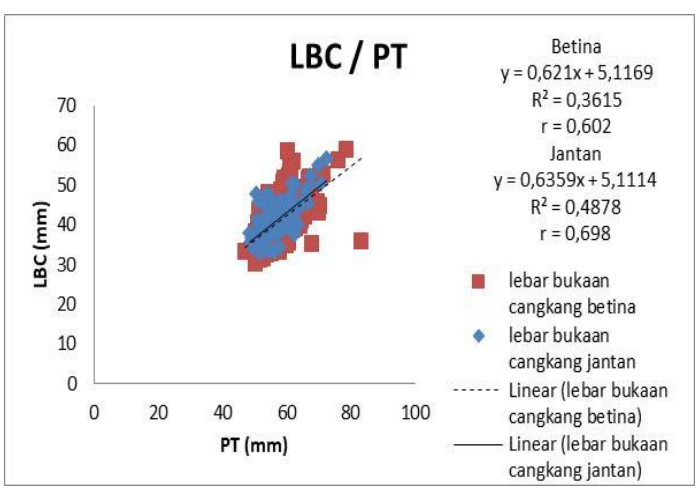

Gambar 3b. Hubungan Lebar Bukaan Cangkang (LBC) dengan Panjang Total (PT)

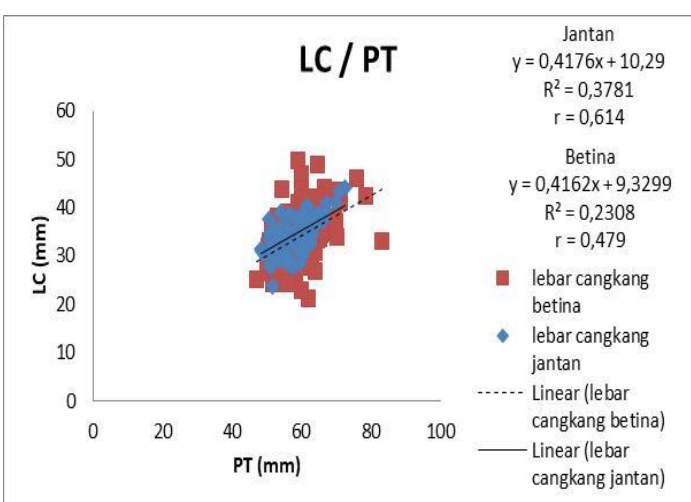

Gambar 3c. Hubungan Lebar Cangkang (LBC) dengan Panjang Total (PT)

Gambar 3a. Hubungan Panjang Total (PT) dengan Panjang Baku (PB) 


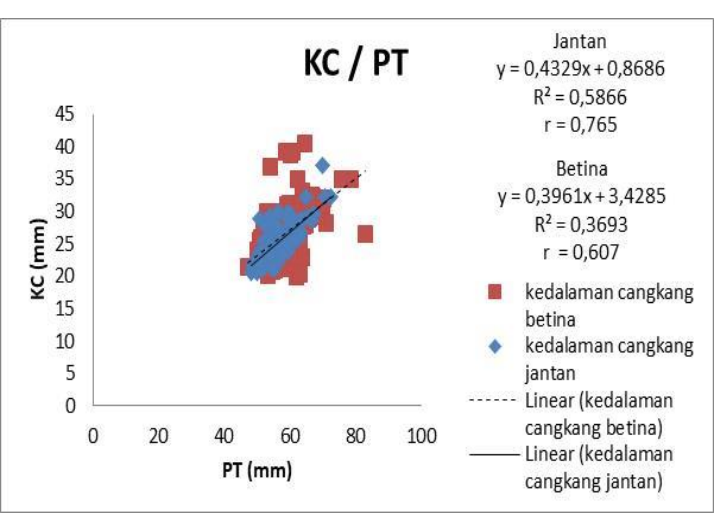

Gambar 3d. Hubungan Kedalaman Cangkang (KC) dengan Panjang Total (PT)

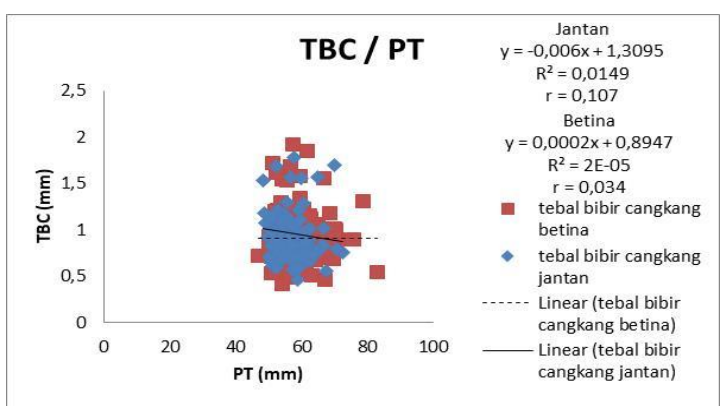

Gambar 3e. Hubungan Tebal Bibir Cangkang (TBC) dengan Panjang Total (PT)

Pada Gambar 3a-e dapat dilihat bahwa bedasarkan hubungan karakteristik tersebut diperoleh pola sebaran data karakter morfometrik seiring dengan pertambahan panjang total (PT) siput gonggong memiliki 2 kelompok, yaitu:

1. Karakter morfometrik panjang baku (PB), lebar bukaan cangkang (LBC), lebar cangkang (LC), dan kedalaman cangkang (KC) pada siput gonggong jantan dan siput gonggong betina tidak mengalami perubahan (tetap) dengan nilai korelasi 0,5-0,8 ini menunjukan nilai korelasinya sedang.

2. Karakter morfometrik tebal bibir cangkang (TBC) pada siput gonggong jantan dan siput gonggong betina mengalami perubahan dengan nilai korelasi $0,-0,5$ ini menunjukan nilai korelasinya lemah.
Menurut Syafriadiman (2006), jika nilai $\mathrm{r}=0$ tidak ada hubungan, 0-0,5 menunjukan korelasi lemah, 0,5-0,8 menunjukan korelasi sedang dan 0,8-1 menunjukan korelasi kuat/erat. Dari penelitian ini didapatkan nilai korelasi sedang dan nilai korelasi lemah. Hubungan yang sangat kuat diduga karena ketersediaan kandungan nutrien pada jenis substrat yang cukup dan juga keadaan lingkungan yang mendukung untuk pertumbuhan siput gonggong pendugaan ini diperkuat dengan pernyataan Chapmand dalam Muzahar (2018) menyatakan bahwa tingkat pertumbuhan siput sebagian besar dipengaruhi oleh kesempatan makan dari jenis dan jumlah makanan terhadap pola bentuk cangkang. Pertambahan karakter panjang total akan mempengaruhi pertambahan panjang karakter lainnya.

\section{Meristik siput gonggong \\ (S. turturella)}

Berdasarkan hasil penelitian jumlah meristik siput gonggong $(S$. turturella) yang didapatkan diukur sebanyak 400 ekor menunjukkan bahwa siput gonggong untuk karakter meristik yaitu jumlah ulir (spire) memiliki jumlah antara 4-8 ulir. Pada meristik tidak dapat membedakan jantan maupun betina.

\section{Pola Pertumbuhan Panjang Berat Siput Gonggong (S. turturella)}

Hubungan panjang total (PT) dan berat siput yang tertangkap selama penelitian adalah sebagai berikut: kisaran panjang 46,98-83,07 $\mathrm{mm}$ dengan kisaran berat 13-46 gram. Hubungan panjang total dengan berat siput dapat dilihat pada Gambar 4. 


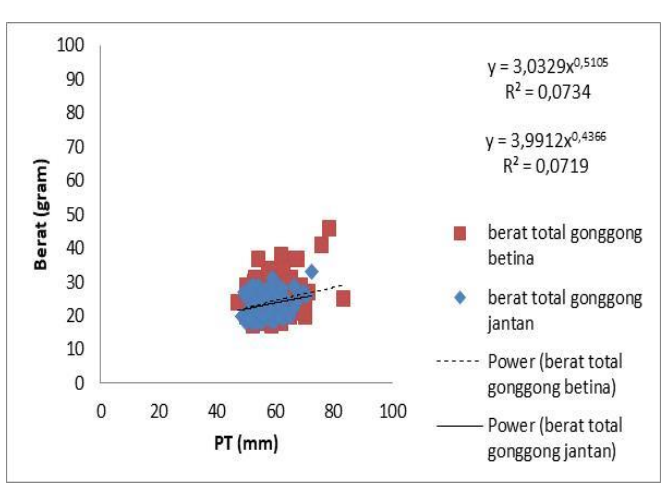

Gambar 4a. Grafik Hubungan Antara Panjang Total (mm) dan Berat Badan (gram) Siput Gonggong Jantan dan Betina.

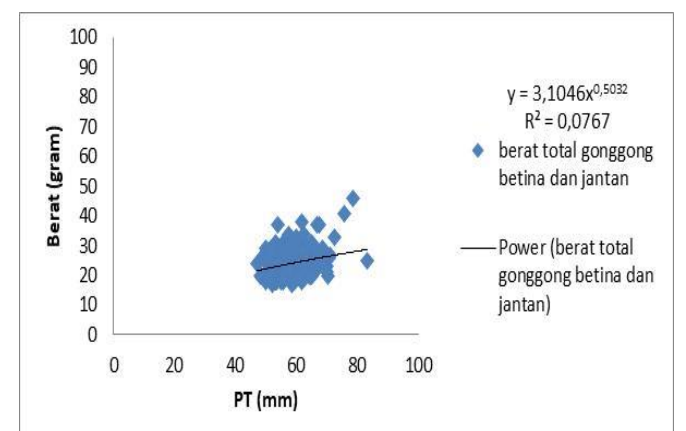

Gambar 4b. Grafik Hubungan Antara Panjang Total $(\mathrm{mm})$ dan Berat Badan (gram) Gabungan Siput Gonggong Jantan dan Betina Nilai $b$ dari persamaan panjang berat adalah 0,510 untuk siput gonggong betina dan 0,436 untuk jantan dan gabungan betina dan jantan nilai $b$ nya yaitu 0,503 , dimana nilai $b$ yang didapatkan untuk siput betina lebih kecil dari 3, atau disebut allometrik negatif yang menunjukan bahwa keadaan siput yang kurus dimana pertambahan panjangnya lebih cepat dari pertambahan beratnya. Sedangkan dengan siput jantan nilai $b$ kecil dari 3 atau disebut juga allometrik negatif yang berarti pertambahan panjang lebih cepat dibandingkan dengan pertambahan berat.

Untuk hubungan panjang total dan berat siput gonggong secara keseluruhan didapatkan nilai b kecil dari 3, disebut juga allometrik negatif yang berarti pertambahan panjang lebih cepat dibandingkan dengan pertambahan berat. Hal ini karena ketersediaan makanan di substrat perairan Pulau Dompak ini tercukupi dan kondisi lingkungan yang masih layak. Secara umum, nilai $b$ tergantung pada kondisi fisiologi dan lingkungan, seperti suhu, $\mathrm{pH}$, letak geografis dan kondisi biologi seperti ketersedian makanan (Muzahar, 2018).

\section{Jenis Substrat Dasar}

Tabel 4. Jenis Substrat di Perairan Pulau Dompak

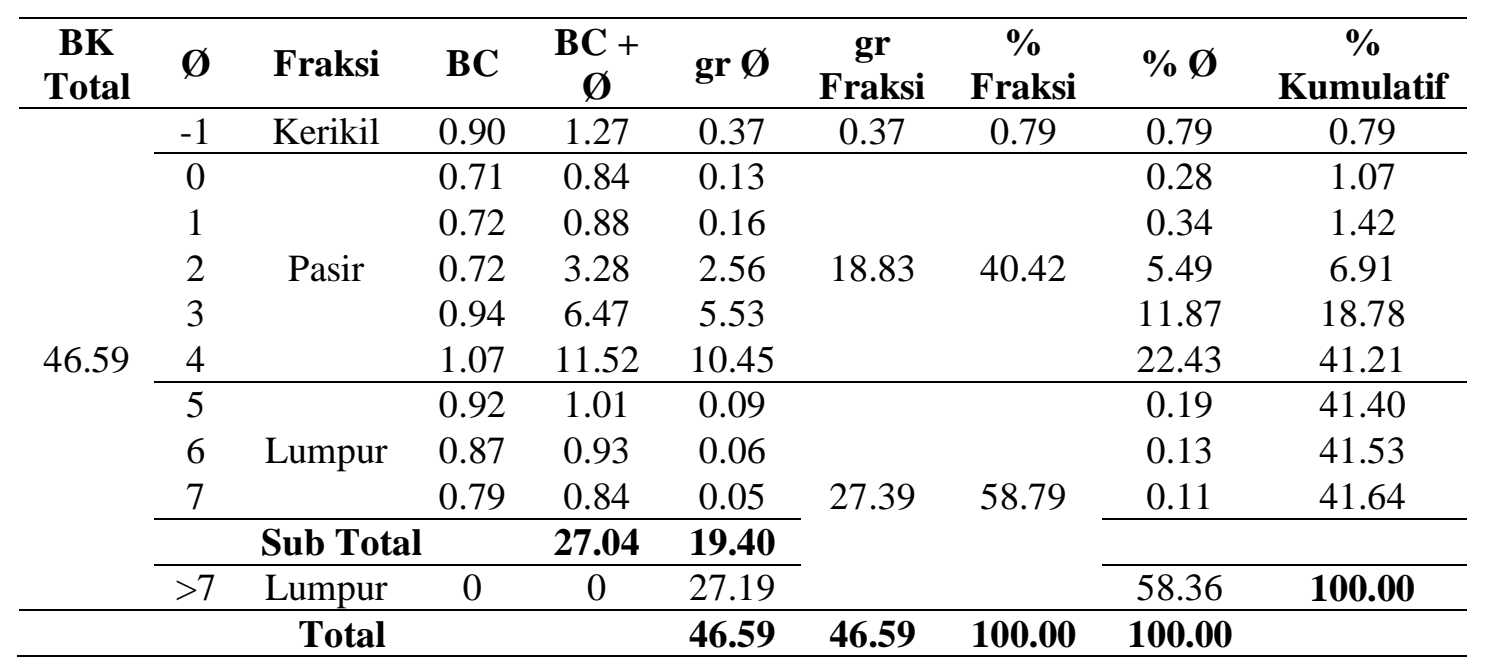


Berdasarkan pada Tabel 4 diatas, didapatkan 2 kelompok bagian besar antara lain lumpur dan pasir. Kemudian setelah dilakukan analisis substrat didapatkan persentase fraksi lumpur yaitu $58,79 \%$, fraksi pasir yaitu $40,42 \%$, maka jenis substrat adalah berbentuk lumpur hingga pasir. Kondisi ini sesuai dengan kehidupan siput gonggong yang menyukai substrat pasir berlumpur. Seperti yang diketahui bahwa lamun merupakan habitat bagi siput gonggong itu sendiri. Hal ini didukung oleh pendapat Siddik (2011) $S$. canarium banyak ditemukan pada substrat pasir berlumpur yang di tumbuhi rumput laut samo-samo (E. accoroides) serta pernyataan dari Riniatsih (2016) bahwa pada tipe substrat halus seperti lumpur, lebih banyak mengandung bahan organik di bandingkan dengan substrat yang lebih kasar.

\section{KESIMPULAN}

Siput gonggong memiliki kisaran panjang total (TL) yaitu 46,98-83,07 mm dan berat 13-46 gram. Hubungan dari 7 karakter morfometrik dan panjang total siput gonggong jantan maupun betina bervariasi. Dari 7 karakter yang diukur terdapat perbedaan karakter antara siput gonggong jantan dan betina, yaitu karakter morfometrik panjang baku (PB), lebar bukaan cangkang (LBC), lebar cangkang (LC), kedalaman cangkang (KC) dan tebal bibir cangkang (TBC). Jumlah meristik spire adalah 4-8 tingkatan untuk siput gonggong betina sedangkan pada siput gonggong jantan mempunyai tingkatan antara 4-9. Sedangkan pola pertumbuhan siput gonggong pada penelitian ini adalah allometrik negative

\section{DAFTAR PUSTAKA}

1. Arianti, N.D., Efrizal, T., Fajri, N.El,. 2013. Abundance Of Dog Conch (Strombus turturella) in Coastal Area Kota Tanjungpinang Subdistrict, Kota Tanjungpinang, KEPRI. University of Riau.

2. BAPPEDA Kabupaten Bintan. 2009. Peta Admin Kabupaten Bintan. Bank Data Bappeda Bintan. Kab. Bintan, Kepulauan Riau.

3. Chapmand, M G. 1997. Relationship Between Shell Shape, Water Reserves, Survival And Growth of Highshore Littorinids Under Experimental Condition in New South Wales, Australia, Jurnal Mollusca Studies, 63:511-529.

4. Eddiwan., Adriman., dan C. Sihotang. 2017. Variasi Morfometrik dan Hubungan Panjang Berat Cangkang Siput Mata Merah (C. obtuse). Universitas Riau. Pekanbaru. Provinsi Riau.

5. Effendie, H. 2003. Telaah Kualitas Air Bagi Pengelolaan Sumberdaya dan Lingkungan Perairan. Kanisius. Yogyakarta. 258 halaman.

6. Muzahar. 2018. Perbandingan Fenotipe Dan Analisa Genotype Lima Varian Siput Gonggong (Dog conch, Laevistrombus sp.) dari Madong-Tj.pinang Sebagai Dasar Pemilihan Spesies Budidaya. Dep. UMRAH. Tanjungpinang.

7. Siddik, J. 2011. Sebaran Spasial dan Potensi Reproduksi Siput Gonggong (Strombus turturela) di Teluk Klabat Bangka Belitung. Tesis. Institut Pertanian Bogor. Bogor. 